\title{
Case report - calcification of the medial collateral ligament of the knee with simultaneous calcifying tendinitis of the rotator cuff
}

\author{
Yama Kamawal ${ }^{*}$, Andre F. Steinert, Boris M. Holzapfel, Maximilian Rudert and Thomas Barthel
}

\begin{abstract}
Background: Calcification of the medial collateral ligament (MCL) of the knee is a very rare disease. We report on a case of a patient with a calcifying lesion within the MCL and simultaneous calcifying tendinitis of the rotator cuff in both shoulders.

Case presentation: Calcification of the MCL was diagnosed both via $x$-ray and magnetic resonance imaging (MRI) and was successfully treated surgically. Calcifying tendinitis of the rotator cuff was successfully treated applying conservative methods.

Conclusion: This is the first case report of a patient suffering from both a calcifying lesion within the medial collateral ligament and calcifying tendinitis of the rotator cuff in both shoulders. Clinical symptoms, radiomorphological characteristics and macroscopic features were very similar and therefore it can be postulated that the underlying pathophysiology is the same in both diseases. Our experience suggests that magnetic resonance imaging and $x$-ray are invaluable tools for the diagnosis of this inflammatory calcifying disease of the ligament, and that surgical repair provides a good outcome if conservative treatment fails. It seems that calcification of the MCL is more likely to require surgery than calcifying tendinitis of the rotator cuff. However, the exact reason for this remains unclear to date.
\end{abstract}

Keywords: Case report, Calcification, Medial collateral ligament, Knee, Rotator cuff, Open surgical repair

\section{Background}

The medial collateral ligament is a very complex apparatus, connecting the medial surface of the femoral condyle to the tibia. Its function is to resist forces applied from the outside of the knee preventing the medial or inner part of the joint from widening. Moreover the MCL is considered a static stabilizer. Its structure is triangular and little expansible. Its origin is located proximally of the medial epicondyle of the femur next to the adductor tubercle, whereas its attachment lies below the medial condyle of the tibia on its medial surface [1].

\footnotetext{
* Correspondence: y-kamawal.klh@uni-wuerzburg.de

Department of Orthopaedic Surgery, Koenig-Ludwig-Haus,

Julius-Maximilians-University Wuerzburg, Brettreichstraße 11, D- 97074

Wuerzburg, Germany
}

(c) 2016 The Author(s). Open Access This article is distributed under the terms of the Creative Commons Attribution 4.0 International License (http://creativecommons.org/licenses/by/4.0/), which permits unrestricted use, distribution, and reproduction in any medium, provided you give appropriate credit to the original author(s) and the source, provide a link to the Creative Commons license, and indicate if changes were made. The Creative Commons Public Domain Dedication waiver (http://creativecommons.org/publicdomain/zero/1.0/) applies to the data made available in this article, unless otherwise stated. condition that is characterized by deposition of calcium-phospate particles - in their crystalline form hydroxyapatite - within a tendon. The aetiology and the factors that predispose to the development of symptoms are still not entirely clear. Different hypotheses have been proposed in the literature but most of them are still not proven or under investigation [2,3] Some authors report that calcification is associated with other pathologic conditions such as renal failure, collagen vascular disease (e.g. dermatomyositis or scleroderma), neurological disorders, Vitamin D overload, tumoral calcinosis or dystrophic calcification [4].

The pathophysiological cascade involves a locally decreased oxygen tension within the affected tissue that leads to fibrocartilaginous metaplasia and eventually to 
calcification of the fibrocartilaginous matrix [4]. This condition is typically associated with a morphologically intact outer structure, in our case an intact rotator cuff and MCL, with a negative history of any trauma. Four stages of calcifying tendinitis have been described: a precalcific, calcific, resorptive, and postcalcific stadium [5].

The typical first clinical manifestation is subacute lowgrade pain that commonly increases during nighttime. Later, during the resorptive stage which involves vascular invasion and migration of phagocytic cells and the development of an edema leading to increased intratendinous pressure, the disease is characterized by sharp acute pain limiting the range of motion of the affected joint [4].

As calcifying tendinitis is usually a self-limiting condition, conservative treatment should be the first line therapy [6-8].

Calcification of the MCL is a very rare disease. In the recent literature only three reports on single symptomatic calcifications of the medial collateral ligament of the knee joint can be found. None of these reports describes the involvement of other parts of the body. To our knowledge, we are the first to demonstrate a case of a patient suffering from both a calcification of the medial collateral ligament of the knee and calcifying tendinitis of the rotator cuff [9-11].

\section{Case presentation}

A 50-year-old caucasian woman was referred to our clinic with a 12 months history of severe, recurrent pain episodes in her right knee. She was a non-smoker, with no other notable family or medical history for any pathological condition. Systemic diseases such as gout, systemic sclerosis, dermatomyositis, and sarcoidosis or any metabolic or endocrine disorders such as hyperparathyroidism and renal failure were excluded. There were no past trauma incidents. Her orthopedic surgeon had diagnosed a calcifying lesion of the MCL 9 months prior to admission to our hospital and had treated her conservatively under the assumption of a calcifying tendinitislike pathological condition. After some temporary pain relief she still suffered from pain at the medial side of the knee and limited range of motion. The conservative management included analgesics, nonsteroidal anti-inflammatory drugs (NSAIDs), electrotherapy and shock wave therapy.

Physical examination of the right knee revealed local pain and swelling over the medial femoral condyle with intact soft tissues and no joint effusion. The patient was able to fully extend her knee but flexion was limited to $120^{\circ}$ with increasing pain at the MCL beginning with $90^{\circ}$ flexion. Patellar mobility was not limited. There was no ligament laxity and clinical tests for detection of meniscus lesions were all negative. There was no sensorimotor deficit. Blood tests showed no evidence of haematological or metabolic abnormality. Knee $\mathrm{x}$-rays revealed linear soft tissue opacity medial to the femoral condyle, suggesting a lobate calcifying lesion within the proximal and middle section of the MCL and surrounding tissue. Anteroposterior, lateral and merchant's views verified the presence of the calcified lesion. MRI without contrast agent of the knee confirmed the presence of this lobate structure, which was characterized by an hypointense signal on the T2 weighted images, located in direct vicinity of the intact MCL in the coronal and sagittal plane, with direct contact to the ligament structure, which was seen in the sagittal and axial plane images of the knee. There were no signs for a mature bony lesion (Figs. 1 and 2).

Due to failure of conservative treatment regimes, we recommended surgery and performed an arthroscopy followed by an open procedure with removal of the calcified lesion. Intraoperatively, we found areas of chondromalacia grade 2 of the patellofemoral compartment and the medial femur condyle. The calcification body was directly attached to the MCL, which was structurally intact. Its consistency was toothpaste-like analogous to the macroscopic appearance of a calcifying tendinitis of

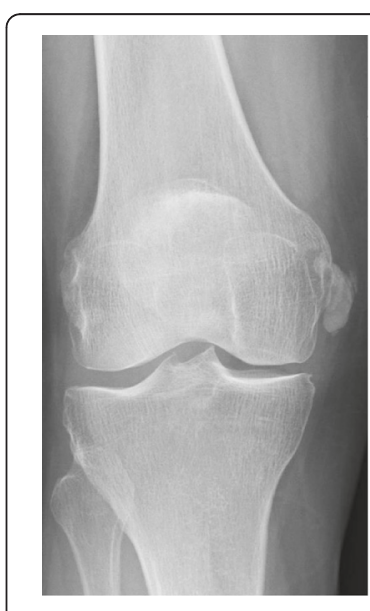

a: anterior-posterior view

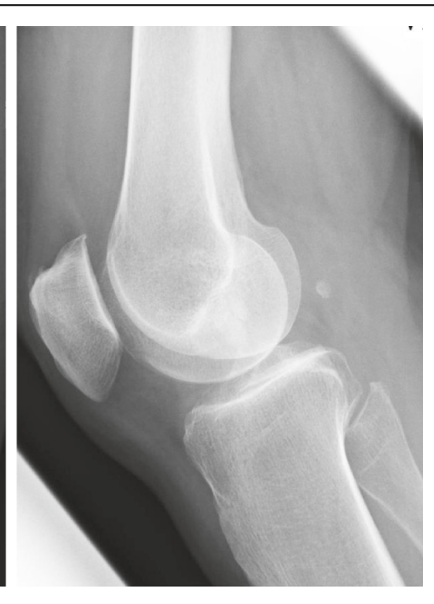

b: lateral view

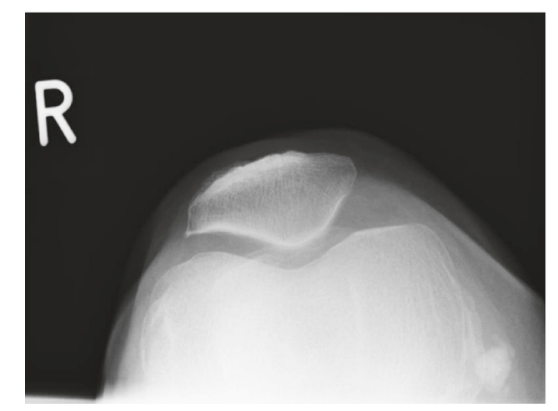

c: merchant's view

Fig. 1 Calcification body within the proximal and middle section of the MCL. It appears as homogeneous and round to ovoid calcification in the soft tissue with well defined margins 

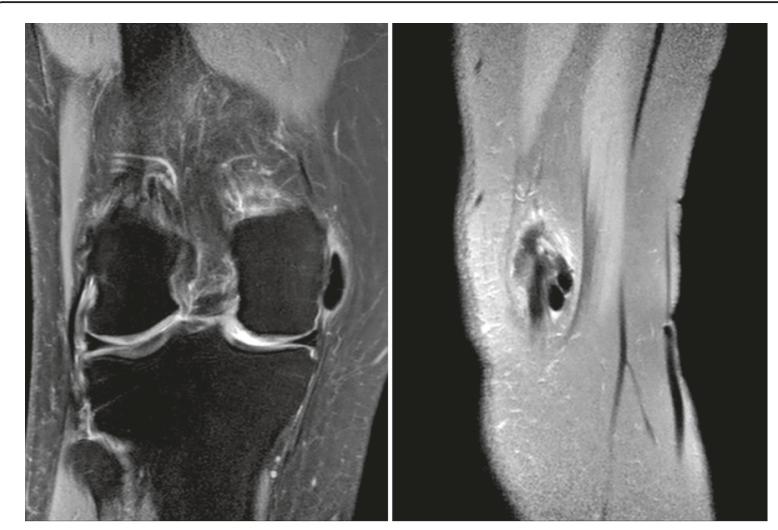

a - PD SPIR coronar

b - PD VISTA SPAIR sagittal

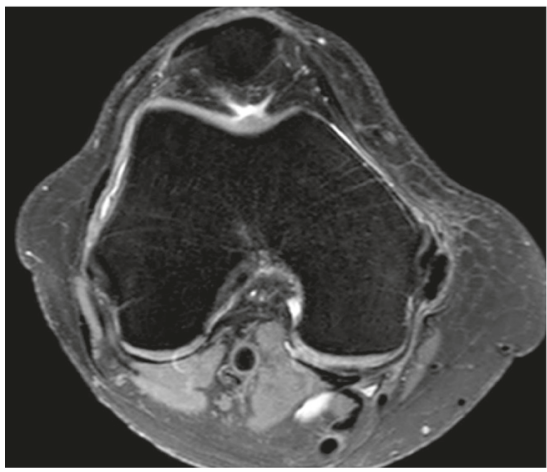

c- PD SPIR transversal

Fig. 2 Rounded area of low signal intensity on all imaging sequences in direct vicinity of the intact $\mathrm{MCL}$, laying directly on the ligament structure

the shoulder. The directly adhering parts of the soft tissues were also removed.

There were no complications during the postoperative course. Weight bearing started with $20 \mathrm{~kg}$ and increased to full weight bearing over 2 weeks, which was well tolerated.

After wound healing and recovery of the soft tissues, the patient was pain-free after 4 weeks. Clinical examination and radiographic evaluation in the next 12 months demonstrated no signs of recurrence without any clinical symptoms (Fig. 3).

During these follow up examinations, the patient described recurrent symptoms of pain and restricted movement of the right shoulder, which had persisted previously for over a year. She had suffered from calcifying tendinitis in both of her shoulder joints 17 years ago. Back then, the $x$-ray pictures had shown calcification bodies near to the greater tubercle at the insertion of the supraspinatus tendon. These lesions had been treated successfully using shockwaves at that time, and had not re-appeared since.

A current MRI survey demonstrated a rupture of the supraspinatus tendon. The patient successfully underwent

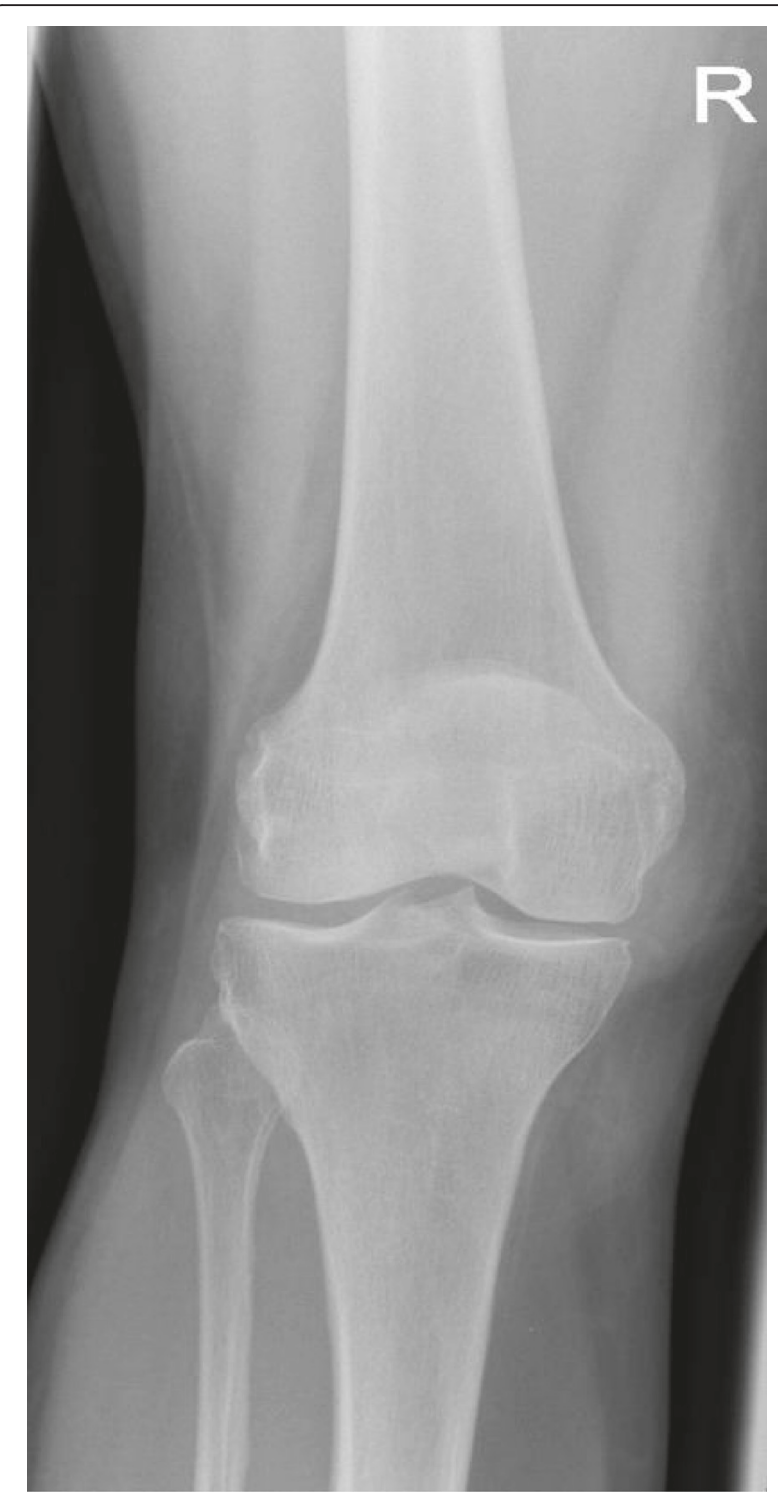

\section{anterior-posterior view}

Fig. 3 X-ray picture 4 months after surgery. Calcification deposit completely removed

a shoulder arthroscopy with a rotator cuff repair in our department. Surgery revealed signs of degenerative changes of the tendon, which had led to the rupture, but no evidence for residual calcium deposits within the supraspinatus tendon were found (Table 1).

\section{Discussion and conclusions}

Articular calcification deposits are most commonly found within the shoulder. Calcifying tendinitis, is one of the most frequent etiologies for shoulder pain. The supraspinatus tendon ( $80 \%$ of cases), followed by the infraspinatus ( $15 \%$ of cases) and subscapularis (5\% of 
Table 1 Timetable

\begin{tabular}{|c|c|c|c|}
\hline \multirow[t]{2}{*}{ Dates } & \multicolumn{3}{|l|}{ Relevant Past Medical History and Interventions } \\
\hline & \multicolumn{3}{|c|}{$\begin{array}{l}\text { 50-year-old caucasian woman, non-smoker, with no other notable family or medical history for any pathological condition. } \\
\text { Systemic diseases such as gout, systemic sclerosis, dermatomyositis, and sarcoidosis or any metabolic or endocrine disorders. } \\
\text { There were no past trauma incidents. }\end{array}$} \\
\hline 25.11.1997 & \multicolumn{3}{|c|}{$\begin{array}{l}\text { She had suffered from calcifying tendinitis in both of her shoulder joints } 17 \text { years ago. Back then, the x-ray pictures had } \\
\text { shown calcification bodies near to the greater tubercle. These lesions had been treated successfully using shockwaves at } \\
\text { that time, and had not reappeared since then. }\end{array}$} \\
\hline Dates & Summaries from Initial and Follow-up Visits & $\begin{array}{l}\text { Diagnostic Testing } \\
\text { (including dates) }\end{array}$ & Interventions \\
\hline Since September 2013 & \multicolumn{3}{|l|}{$\begin{array}{l}\text { history of severe, recurrent pain episodes } \\
\text { in her right knee }\end{array}$} \\
\hline 10.12.2013 & $\begin{array}{l}\text { a calcifying lesion of the MCL was } \\
\text { diagnosed }\end{array}$ & x-rays, ultrasound, MRI & $\begin{array}{l}\text { conservative management included analgesics, } \\
\text { non-steroidal anti-inflammatory drugs, } \\
\text { electro-therapy and shock wave therapy }\end{array}$ \\
\hline 18.09.2014 & \multicolumn{2}{|l|}{$\begin{array}{l}\text { Due to failure of conservative treatment } \\
\text { regimes, we recommended surgery }\end{array}$} & $\begin{array}{l}\text { arthroscopy followed by an open procedure } \\
\text { with removal of the calcified lesion. }\end{array}$ \\
\hline 04.03 .2015 & rupture of the supraspinatus tendon. & MRI & shoulder arthroscopy with a rotator cuff repair \\
\hline $\begin{array}{l}31.10 .2014 \\
08.01 .2015 \\
09.04 .2015 \\
02.10 .2015\end{array}$ & $\begin{array}{l}\text { Clinical examination and radiographic } \\
\text { evaluation demonstrated no signs of } \\
\text { recurrence without any clinical symptoms }\end{array}$ & x-rays & \\
\hline
\end{tabular}

cases) tendon, is most commonly affected [8]. The prevalence for these lesions is 3-20\% in asymptomatic patients and 7-54\% in symptomatic patients, reaching its peak between 30-50 years of age [2]. Women seem to be affected more often than men, at a ratio of 3 to 2 [7].

After the shoulder, the hip is the second frequent location for the development of calcification deposits, most commonly found in the gluteus medius tendon at the greater trochanter. Furthermore the posterolateral femoral attachment of the gluteus maximus can be involved. Other areas of involvement include the iliopsoas tendon insertion at the lesser trochanter, and the ischial origins of the common hamstring tendons [12].

Another joint which can be affected is the elbow, including the bursa and the flexor and extensor tendon complexes at the epicondylar origins, the triceps, brachialis, and biceps tendons. It can also occur in the medial and lateral collateral ligamentous complexes [13, 14].

Other parts of the upper extremity that can be involved are the wrist and the hand. The wrist is more frequently affected than the hand. The pisiform insertion site of the flexor carpi ulnaris tendon is reportedly the main site of involvement in the wrist. In the hand, deposits in the metacarpophalangeal and interphalangeal regions are not uncommon [15].

In the ankle and foot, calcifications can involve a plethora of structures, among them the flexor hallucis longus and brevis and the peroneus tendons [16].

In the knee, calcification deposits can occur in the joint, on the extrasynovial anterior or posterior cruciate ligament $[17,18]$. Usually they can be found near osseous attachments of the ligaments or the popliteus tendon rather than at other structures $[3,19,20]$.

Calcification deposits typically present on MR imaging as rounded areas of low signal intensity on all imaging sequences. The deposits are particularly conspicuous on gradient echo imaging. In the acute symptomatic phase the process has an aggressive appearance with marrow and soft tissue edema that may mimic infection, trauma, or neoplasm [21].

An association between acute pain attacks and histological evidence of calcium resorption has been described previously [7]. Most symptoms resolve within 23 weeks under conservative treatment. NSAIDs are an essential part of the basic treatment strategy. If there is no relief of the symptoms under NSAIDs or the drugs cannot be tolerated, local corticosteroid injections, oral steroids, shockwave therapy and needling are further therapeutic options. If conservative management fails, deposits can be removed surgically or via image-guided aspiration [22].

Posttraumatic calcification can appear in different locations, including the medial collateral ligament. The term 'Pellegrini-Stieda lesion' is used for the latter finding, and is named after both doctors Pellegrini and Stieda, who described this phenomenon for the first time in 1905 and 1907, respectively. However, it was suggested by Koenig, Koehler and Pfister in 1909, that there are Pellegrini-Stieda shades, who aren't necessarily caused by trauma and may have other etiologies [23-25]. 
The Pellegrini-Stieda disease is a relatively rare phenomenon and is commonly associated with sports injuries. It is thought that Pellegrini-Stieda lesions are post-traumatic ossifications following an avulsion injury to the attachment of the medial collateral ligament, at the medial femoral condyle. Tearing fibres of the ligament at its superior femoral attachment can cause hematoma or inflammatory edema. The soft tissue can be also affected and absorbs calcium salts during the later stages of the disease. This mechanism takes place approximately 2-6 weeks after the trauma. In the next stage of the disease, the calcium salts can be resorbed which results in a degradation of the lesion or an ossified mesh can develop, which usually gets connected to the femoral condyle by a pedicle within the next 6 months. The calcification of the superior femoral attachment is in most cases characteristic, confirmed by $\mathrm{x}$-ray and often associated with ruptures of the anterior cruciate ligament [26, 27].

Calcification deposits typically present on MRI imaging as rounded areas of low signal intensity on all imaging sequences. The deposits are particularly conspicuous on gradient echo imaging. In the acute symptomatic phase the process has an aggressive appearance with marrow and soft tissue edema that may mimic infection, trauma, or neoplasm [21].

Most of the patients with this post-traumatic calcification of the MCL are asymptomatic. The term PellegriniStieda syndrome is only used if the symptoms can be directly associated with the appearance of the PellegriniStieda shadow [28]. They can increase within a few weeks or months, and can result in nearly completely restricted range of motion. The pain and swelling are located on the medial side of the knee [29-31].

The kind of calcification of the MCL presented in our case seems to be similar to the Pellegrini-Stieda syndrome at the first glance, but has to be distinguished from this entity in terms of its pathophysiology and -morphology. The calcification body in our case was not localized at the insertion of the ligament and also differed in its radiological morphology and appearance. Ossification of Pellegrini-Stieda type lesions are of concave and flattened, whereas the calcification seen in our case was rounded and lobate, clearly circumscribed and dense, corresponding to type 1 of the radiological classification of calcifying tendinitis by Gaertner and Heyer [32]. The intraoperative paste-like findings corresponded to the intraoperative characteristic appearance of a calcifying tendinitis of the rotator cuff. Therapy was analogous to the management of this well known pathologic entity of the rotator cuff. After all conservative treatment modalities were exhausted, surgical excision was performed. The postal-surgical course was uneventful. Six months after the surgery, the patient was completely free of pain and was able to perform her everyday activities without any limitation.

This is the first reported case of a patient suffering from both a calcifying lesion of the medial collateral ligament of the knee and calcifying tendinitis of the rotator cuff in both shoulders.

In the literature three reports with seven cases describing single symptomatic calcifications of the medial collateral ligament of the knee can be found. Five patients were successfully treated by surgical resection, two patients were treated conservatively with a positive result. There were no reports that one of them had other parts of the body involved in a calcification process [9-11].

In the precedent medical history of our patient, she had suffered from calcifying tendinitis in both shoulders, and had successfully been treated conservatively. Because of a rupture of the tendon of the musculus supraspinatus the patient required surgery 17 years later, which revealed no remaining or recurrent calcification bodies.

Our experience suggests that magnetic resonance imaging and $\mathrm{x}$-ray evaluation are invaluable tools in the diagnosis of this condition and that surgical repair provides a good outcome, if conservative treatment fails.

In contrast to calcifying tendinitis of the rotator cuff, calcification of the MCL is a very rare disease. Because the patient in our report suffered from both of these diseases, one can come to the conclusion that there is probably the same kind of etiology, however, the exact mechanism of the calcium deposition involved in these two conditions is not entirely clear. Analogous to the rotator cuff, conservative treatment regimes can be used, although it seems that the calcification of the MCL is a condition that is more resistant to conservative therapy than common calcifying tendinitis of the rotator cuff. A possible reason could be the difference in the pathomechanism of the two lesions. It is well known that the integrity of the rotator cuff can be affected due to pathological mechanisms such as inner and outer impingement leading to structural changes. On the other hand the pathological mechanisms leading to an impairment of the MCL are different. In general, the MCL is damaged by extrinsic indirect stresses which might result in different structural changes as seen in the tendon [33, 34].

\section{Abbreviations}

MCL, medial collateral ligament; MRI, magnetic resonance imaging; NSAIDs, nonsteroidal anti-inflammatory drugs

\section{Funding}

This publication was funded by the University of Wuerzburg in the funding programme Open Access Publishing.

Availability of data and materials

Patient data can be provided upon request. 


\section{Authors' contributions}

YK and AFS prepared the figures and collected the data. TB performed the surgery. MR provided guidance in patient management. YK, BH, AFS, MR and TB wrote the manuscript. All authors read and approved the final manuscript.

\section{Competing interests}

All authors declare that they have no competing interests.

\section{Consent for publication}

Written informed consent was obtained from the patient for publication of this case report and any accompanying images.

\section{Ethics approval and consent to participate}

Not applicable.

\section{Received: 8 March 2016 Accepted: 29 June 2016}

\section{Published online: 13 July 2016}

\section{References}

1. LaPrade RF, Moulton SG, Nitri M, Mueller W, Engebretsen L. Clinically relevant anatomy and what anatomic reconstruction means. Knee Surg Sports Traumatol Arthrosc. 2015;23(10):2950-9

2. Harmon $\mathrm{H}$. Methods and results in the treatment of 2,580 painful shoulders, with special reference to calcific tendonitis and the frozen shoulder. Am J Surg. 1958;95:527-44.

3. Rehak D, Fu F. Calcification of tendon of the vastus lateralis. A case report. Am J Sport Med. 1992;20:227-9.

4. Oliva F, Via A, Maffulli N. Physiopathology of intratendinous calcific deposition. BMC Med [Internet]. 2012;10(1):95. Available from: http://www. biomedcentral.com/1741-7015/10/95.

5. Mt E. Calcific tendinitis of the rotator cuff. World J Orthop. 2016;1(7):55-60.

6. Hayes CW, Conway WF. Calcium hydroxyapatite deposition disease. Radiographics. 1990;10(6):1031-48.

7. Uhthoff HK, Sarkar K. Calcifying tendinitis. Baillieres Clin Rheumatol. 1989;3(3):567-81.

8. Bianchi S, Martinoli C. Shoulder. Ultrasound of the Musculoskeletal System [Internet]. 2007. p. 189-331. Available from: http://dx.doi.org/10.1007/978-3540-28163-4 6.

9. Chang W, Huang GS, Lee CH, Kao HW, Chen CY. Calcification of medial collateral ligament of the knee: an uncommon cause of medial knee pain. J Clin Rheumatol. 2006;12:204-5.

10. Mansfield HL, Trezies A. Calcific tendonitis of the medial collateral ligament. Emerg Med J [Internet]. 2009:26(7):543. Available from: http://www.ncbi.nlm. nih.gov/pubmed/19546285.

11. Muschol M, Muller I, Petersen W, Hassenpflug J. Symptomatic calcification of the medial collateral ligament of the knee joint: A report about five cases. Knee Surg Sports Traumatol Arthrosc [Internet]. 2005;13(7):598-602. Available from: http://www.ncbi.nlm.nih.gov/pubmed/15726327.

12. Berney J. Calcifying peritendinitis of the gluteus maximus tendon. Radiology. 1972:102:517-8.

13. Steinbach LS. Calcium pyrophosphate dihydrate and calcium hydroxyapatite crystal deposition diseases: Imaging perspectives. Radiologic Clinics of North America. 2004. p. 185-205.

14. Sakamoto K, Kozuki K. Calcific tendinitis at the biceps brachii insertion of a child: a case report. J shoulder Elb Surg. 2002;11:88-91.

15. Moyer R, Bush D, Harrington T. Acute calcific tendinitis of the hand and wrist: a report of 12 cases and a review of the literature. J Rheumatol. 1989:16:198-202.

16. Weston W. Case reports; peroneal tendinitis calcarea. Br J Radiol. 1959;32:134-5.

17. Tsujii A, Tanaka $Y$, Yonetani $Y$, luchi $R$, Shiozaki $Y$, Horibe S. Symptomatic calcification of the anterior cruciate ligament: A case report. Knee. 2012;19(3):223-5.

18. Koukoulias NE, Papastergiou SG. Isolated posterior cruciate ligament calcification. BMJ Case Rep [Internet]. 2011;2011. Available from: http://www. ncbi.nlm.nih.gov/pubmed/22669889

19. Tibrewal SB. Acute calcific tendinitis of the popliteus tendon - An unusual site and clinical syndrome. Ann R Coll Surg Engl. 2002:84(5):338-41.

20. Anderson S, Bosshard C, Steinbach L, Ballmer F. MR imaging of calcification of the lateral collateral ligament of the knee: a rare abnormality and a cause of lateral knee pain. Am J Roentgenol. 2003;181:199-202.
21. Yang I, Hayes CW, Biermann JS. Calcific tendinitis of the gluteus medius tendon with bone marrow edema mimicking metastatic disease. Skeletal Radiol. 2002;31(6):359-61.

22. Farin PU, Jaroma $\mathrm{H}$, Harju A. Rotator cuff calcifications: Treatment with ultrasound-guided percutaneous needle aspiration and lavage. Skeletal Radiol. 1996;25(6):551-4

23. Murray R, Jacobsen $\mathrm{G}$. The radiology of skeletal disorders: exercise in diagnosis. Vol. II \& III, 2nd ed. Edinburgh: Chuchill Livingstone; 1977.

24. Resnick D, Niwaaynia G. Diagnosis of bone and joint disorders, vol. 3. Philadelphia: WB Saunders Company; 1981.

25. Shanks SC, Kerley P. A text book of $x$-ray diagnosis Vol IV. Philadelphia: WB Saunders Company; 1959.

26. Kogon P, Tchoryk J, Fleming O. Pellegrini-Stieda disease. J Can Chiropr Assoc. 1987;31(4):191-2.

27. Turner JW, Syed IB, Spencer RP. Two unusual causes of peripatellar nonmetastatic positive bone scans in patients with malignancies: case reports. J Nucl Med [Internet]. 1976;17(8):693-5. Available from: http://www. ncbi.nlm.nih.gov/entrez/query.fcgi?cmd=Retrieve\&db=PubMed\&dopt= Citation\&list_uids=932812

28. Wang J, Shapiro M. Pellegrini-Stieda syndrome. Am J Orthop. 1995;24:493-7.

29. Schünke M, Schulte E, Schumacher U. PROMETHEUS Lernatlas der Anatomie. Allgemeine Anatomie und Bewegungssystem. 2005. p 390-401.

30. Shanker VS, Gadikoppula S, Loeffler MD. Post traumatic osteoma of tibial insertion of medial collateral ligament of knee joint. Br J Sports Med [Internet]. 1998;32(1):73-4. Available from: http://www.ncbi.nlm.nih.gov/ pubmed/9562171

31. Altschuler EL, Bryce TN. Pellegrini-Stieda Syndrome. N Engl J Med [Internet]. 2006;354(1):e1. Available from: http://www.nejm.org/doi/abs/10.1056/ NEJMicm040406.

32. Gärtner J, Heyer A. Calcific tendinitis of the shoulder. Orthopade. 1995:24:284-302

33. Tagg CE, Campbell AS, McNally EG. Shoulder impingement. Semin Musculoskelet Radiol. 2013:17(1):3-11.

34. Phisitkul $P$, James SL, Wolf BR, Amendola A. MCL injuries of the knee: current concepts review. lowa Orthop J [Internet]. 2006;26(Mc):77-90. Available from: http://www.pubmedcentral.nih.gov/articlerender. fcgi?artid=1888587\&tool=pmcentrez\&rendertype=abstract.

\section{Submit your next manuscript to BioMed Central and we will help you at every step:}

- We accept pre-submission inquiries

- Our selector tool helps you to find the most relevant journal

- We provide round the clock customer support

- Convenient online submission

- Thorough peer review

- Inclusion in PubMed and all major indexing services

- Maximum visibility for your research

Submit your manuscript at www.biomedcentral.com/submit
Biomed Central 